\title{
Biology and genome of Trichinella spiralis $^{*}$
}

\author{
Makedonka Mitreva ${ }^{\S}$, Genome Sequencing Center, Washington \\ University School of Medicine, St. Louis, MO 63108 USA \\ Douglas P. Jasmer, Department of Molecular Microbiology and \\ Pathology, College of Veterinary Medicine, Washington State University, \\ Pullman, WA 99164-7040, USA
}

\section{Table of Contents}

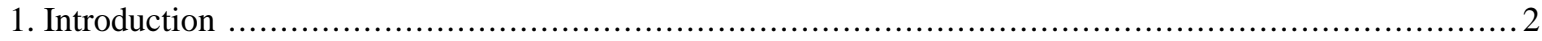

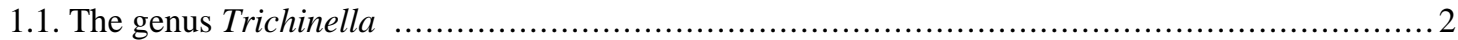

1.2. Geographic range ...........................................................................

1.3. Phylogenetic position of Trichinella within the phylum Nematoda .................................2

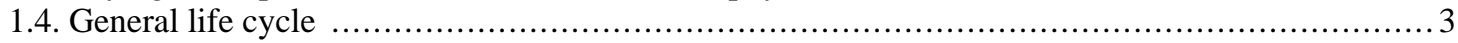

1.5. Zoonotic Transmission and Clinical disease ...................................................

2. Molecular and cellular interactions with the host .......................................................... 6

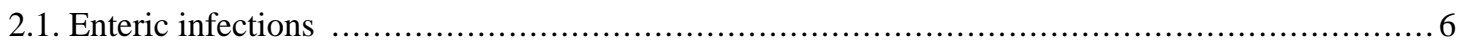

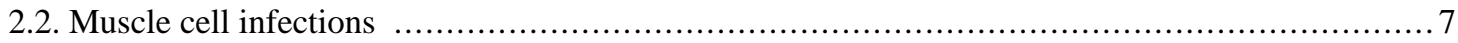

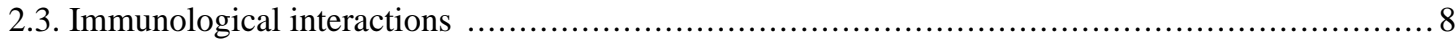

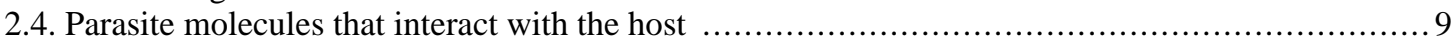

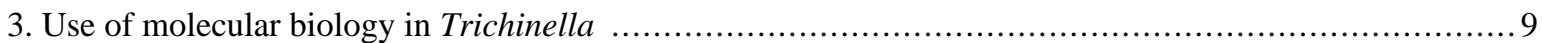

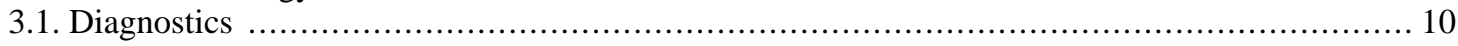

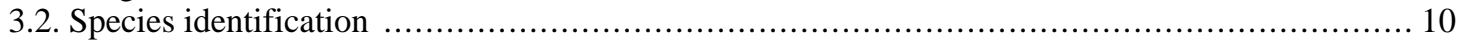

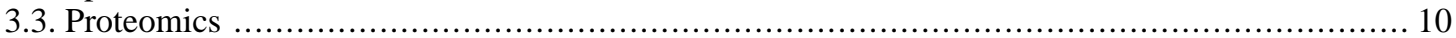

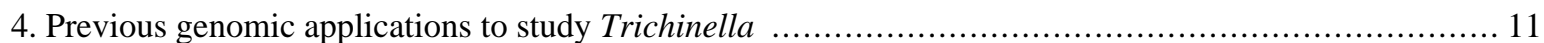

5. Current genome sequencing project for Trichinella spiralis ........................................ 12

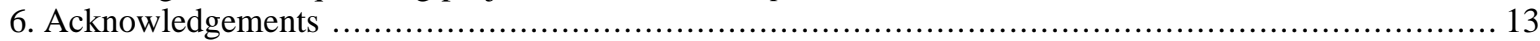

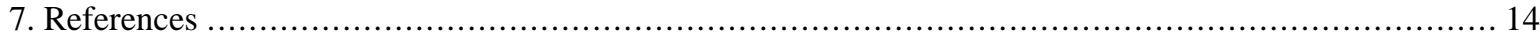

*Edited by Jonathan Hodgkin. Last revised October 5, 2006. Published November 23, 2006. This chapter should be cited as: Mitreva, M. and Jasmer, D.P. Biology and genome of Trichinella spiralis (November 23, 2006), WormBook, ed. The C. elegans Research Community, WormBook, doi/10.1895/wormbook.1.124.1, http://www.wormbook.org.

Copyright: () 2006 Makedonka Mitreva and Douglas P. Jasmer. This is an open-access article distributed under the terms of the Creative Commons Attribution License, which permits unrestricted use, distribution, and reproduction in any medium, provided the original author and source are credited.

${ }^{\S}$ To whom correspondence should be addressed. E-mail: mmitreva@ watson.wustl.edu 


\begin{abstract}
Clade I nematode species in the genus Trichinella can cause infections in humans that lead to mortality and serious morbidity. There are currently eight recognized species or genotypes that comprise this genus. The species display diverse biological characteristics, the evolutionary significance of which recently has been extensively clarified. Some of that diversity translates into variable importance as zoonotic pathogens, with $T$. spiralis having the highest significance. Trichinellosis has re-emerged as an important zoonotic infection in various parts of the world, reminding us that control of this infection depends on persistent vigilance. Trichinella species display unique and biologically interesting complexity in interactions with host cells that they inhabit. Significant progress has been made toward understanding details of these interactions. Progress on transcriptomics, proteomics and now genomics offers exciting prospects for accelerating advances in future research. An overview of these parasites regarding biology, significance as zoonotic pathogens and selected research topics is presented here.
\end{abstract}

\title{
1. Introduction
}

\subsection{The genus Trichinella}

Nematodes in the genus Trichinella infect a broad range of mammals, birds and reptiles. These parasites alternate during their life cycle between enteric stages and skeletal muscle stages within their hosts. Eleven known species or genotypes comprise the genus, which is composed of two main clades: species in which the host muscle cells they invade become surrounded by a collagen capsule (encapsulated) and those in which no encapsulation occurs (e.g., Zarlenga et al., 2004). The five species (and three genotypes yet to be defined taxonomically) that comprise the encapsulated clade parasitize only mammals, whereas of the three species that comprise the nonencapsulated clade, one infects mammals and birds. The other two species infect mammals and reptiles (Pozio et al., 2004). There are only two of these parasites, T. papuae and T. zimbabwensis, known to complete their entire life cycle independently of whether the host is warm-blooded or cold-blooded. Historically, T. spiralis has been the most important cause of human infections and much of the biological information discussed for the genus in this chapter comes from studies on this species. $T$. spiralis belongs to the first clade, members of which inhabit host muscle cells that become encapuslated. It is noteworthy that the collagen capsule referred to is a host characteristic that has phylogenetic implications for the parasite (see section 1.3). Hence, the induction of the capsule may reflect an adaptation in interactions with the host that facilitated speciation and diversification.

\subsection{Geographic range}

Species of Trichinella inhabit a broad geographic range from the arctic to the tropics, however, distributions of individual species are more restricted, with encapsulated species generally demonstrating adaptation to colder climates than nonencaspulated species. With the exception of some nonencapsulated species noted (see section 1.1), major host groups of Trichinella spp. are domestic and sylvatic swine (Sus scrofa), synanthropic animals such as the brown rat, the armadillo, cats, dogs, and a broad range of sylvatic carnivores. Because it has been passively imported into most continents due to its high infectivity to swine and synanthropic rats (Pozio, 2001), T. spiralis shows a cosmopolitan distribution in temperate and equatorial climatic zones. Several recent reviews summarize the presence of trichinellosis in individual countries, such as Argentina (Ribicich et al., 2005), Hungary (Sreter et al., 2005), China (Liu and Boireau, 2002), Mexico (Flisser et al., 2002) and Greece (Sotiraki et al., 2001). Furthermore, due to political and economic changes in southeastern Europe, a re-emergence of trichinellosis has been reported in countries of this region (Cuperlovic et al., 2005), and recent human outbreaks have been reported in Germany, Italy and United Kingdom (Pozio and Marucci, 2003).

\subsection{Phylogenetic position of Trichinella within the phylum Nematoda}

Molecular phylogenetics has defined three major nematode classes which can be further divided into five Clades (Blaxter et al., 1998): Dorylaimia (also Clade I of Blaxter et al., 1998), Enoplia (also Clade II), and Chromadorea (including Spirurina-Clade III, Tylenchina-Clade IV, and Rhabditina-Clade V). Parasitism has arisen multiple times during nematode evolution and all major clades include parasitic species. The model free-living nematode, C. elegans, is a member of Rhabditina (Clade V) and T. spiralis is a member of Dorylaimia (Clade I) making these examples some of the most distant species within the Nematoda. 
The estimated divergence of the nematodes from arthropods occurred 800-1,000 MYA (Blaxter, 1998). Based on previously reported reconstruction of the ancient history of the nematodes, the most recent common ancestor of the extant species C. elegans and Trichostrongylus colubriformis (Clade V), Nippostrongylus brasiliensis (Clade V), Ascaris suum (Clade III) and Pseudoterranova decipiens (Clade III) lived about 550 MYA (Vanfleteren et al., 1994). When those estimates were made, the globin and cytochrome c amino acid sequences were not available from T. spiralis. With the availability of these sequences from a T. spiralis EST database (Mitreva et al., 2004), divergence of lineages leading to $C$. elegans and T. spiralis was estimated at 700 MYA (M.L. Blaxter, personal communication). While sequence data from these two genes is insufficient for reliable estimates on dates for speciation, the globin gene yielded a date of 115 MYA for divergence between C. elegans and C. briggsae (M.L. Blaxter, personal communication), a value supported by (Stein et al., 2003). This consideration would produce an estimate for divergence of lineages leading to C. elegans and T. spiralis at >600 MYA.

The first robust and comprehensive analysis of the phylogeny and biogeographic history of Trichinella was recently reported, based on variation in several genetic loci (Zarlenga et al., 2006). The basal Dorylaimia lineage (nematode Clade I) which contains Trichinella also contains the free-living Mononchida, the plant parasitic Dorylaimida and the entomophagous Mermithida. These nematodes share features of early embryogenesis (Voronov et al., 1998) and small-subunit (SSU) rDNA sequences (Blaxter et al., 1998). The genus Trichinella is a monophyletic lineage in the Trichinellidae, which diverged 275 MY (Permian) from the putative sister Trichuridae. The 11 known species of this genus diverged into 2 distinct clades. Agreement for that divergence comes from both biological considerations, Trichinella clade I are encapsulated and Clade II are nonencapsulated, and genetic data. The findings indicate an especially close relationship between the non-encapsulated species, T. papuae and T. zimbabwensis, and between freeze-tolerant encapsulated genotypes, T. nativa and Trichinella T6, where T. spiralis is basal to all encapsulated species. The separation between nonencapsulated and encapsulated lineages occurred 15-20 MYA (Miocene; http://www.ucmp.berkeley.edu/help/timeform.html), and species appearing at or near the base of the encapsulated clade i.e. T. spiralis and T. nelsoni, likely diverged less than 10 MYA (Figure 1; Zarlenga et al., 2006).

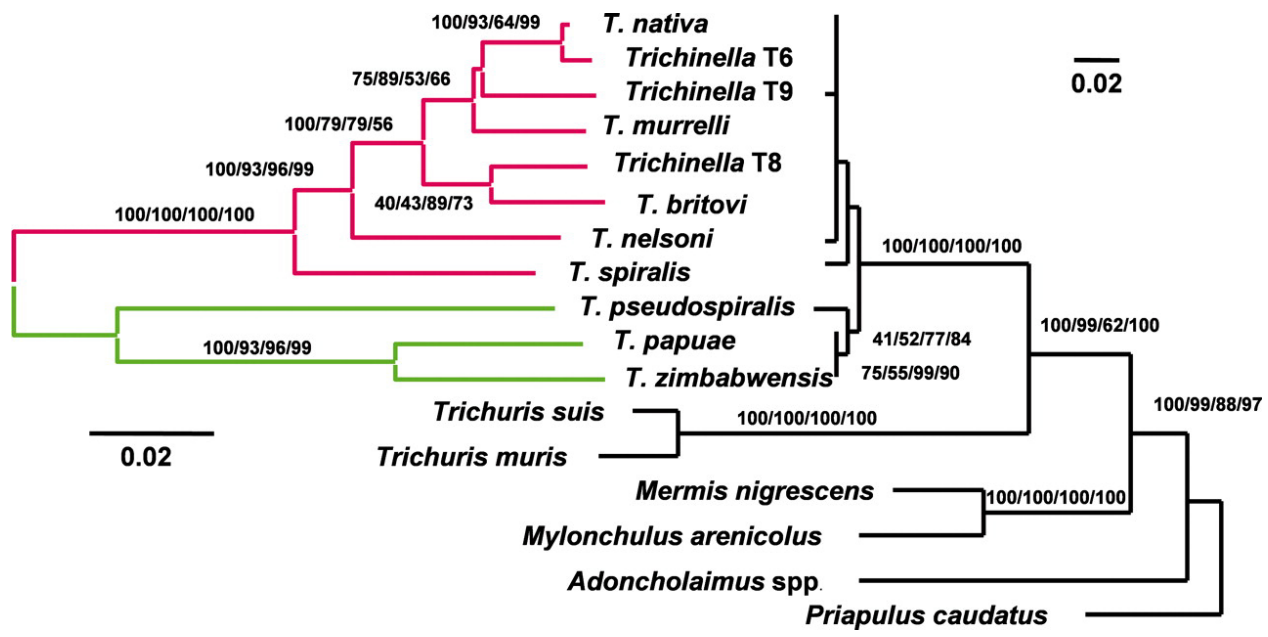

Figure 1. Midpoint rooted minimum evolution trees reconstructed from all known encapsulated (red) and nonencapsulated (green) species and genotypes of Trichinella based on the variation in mitochondrial LSU and COI DNA (on the left) and SSU rDNA (on the right). Topological support is indicated by Bayesian posterior probabilities and by ML, minimum evolution (using ML distances), and parsimony bootstrap replicate analyses (B/ML/ME/P). Bootstrap support was reconstructed from 100-bp replicates. Reprinted with permission from Zarlenga et al., (2006), Copyright (2006) National Academy of Sciences, U.S.A.

\subsection{General life cycle}

T. spiralis (Owen, 1835) is a relatively small nematode with adult females 1.4 to $4 \mathrm{~mm}$, adult males 1.4 to 1.8 $\mathrm{mm}$ and muscle larvae of approximately $1 \mathrm{~mm}$ (Figure 2). The life cycle of the parasite (Figure 3 ) begins with the enteral phase of infection when a person or an animal eats contaminated meat containing first stage muscle larvae. Digestive juices from the stomach (pepsin and hydrochloric acid) dissolve the capsule-like cyst and release the larvae which pass into the small intestine, where they invade the columnar epithelium (Katz, 1989). Shortly thereafter, the larvae molt four times, (10 through $28 \mathrm{H}$ post-oral ingestion, poi), mature to adults that mate (30-34 $\mathrm{H}$ 
poi; Figure 2, panel A). Female worms can produce 500-1,500 newborn larvae (immature L1) during a life span, before expulsion by the host immune system. The migratory phase of infection begins when these newborn larvae are passed into tissue, enter lymphatics and then enter the general circulation at the thoracic duct. These larvae are widely distributed in tissue by the circulation and eventually make their way through the capillaries (tiny blood vessels) into the muscle fibers, which intiates the muscle phase of infection. Once in the muscle fibers, they encyst (Figure 2, panel B), undergo development, become infective within 15 days and remain for months to years.

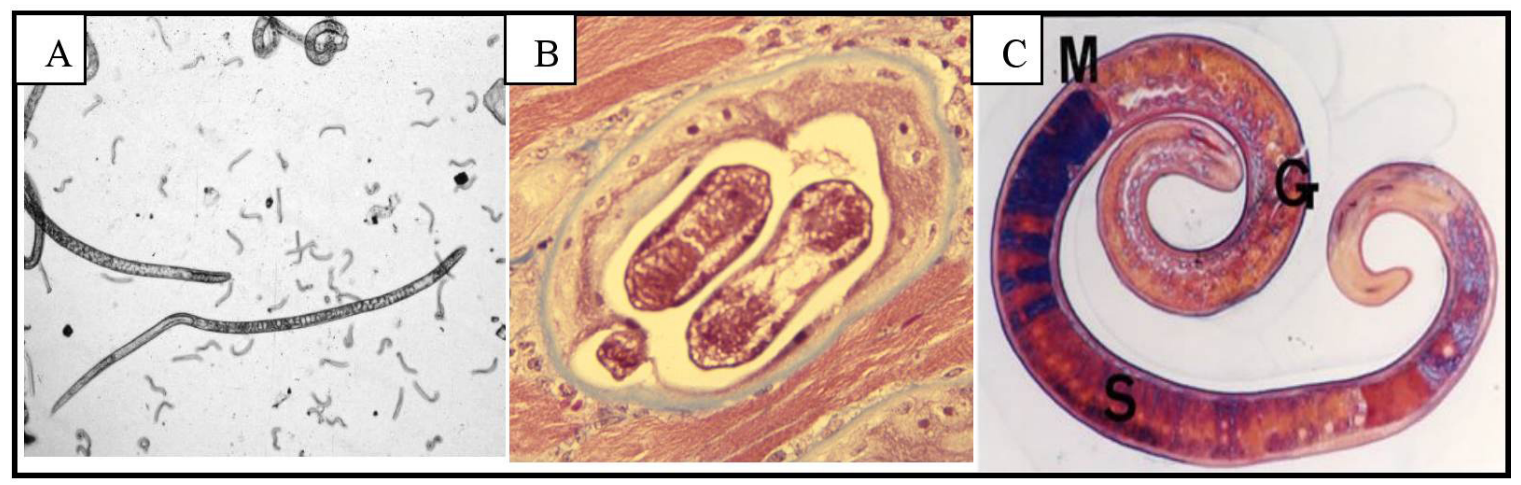

Figure 2. Life-cycle stages of $\boldsymbol{T}$. spiralis. A. Adult worms that developed in the small intestine following oral infection with muscle larvae; the small worms are newborn larvae (immature L1), which are infective to muscle. B. Infective muscle larva in altered muscle cell surrounded by a collagen capsule (blue). C. Infective muscle larva, Azan staining of longitudinal section of excysted larvae. M: midgut, G: genital primordium, S: stichocyte. (Panel C, photo courtesy of Yuzo Takahashi, Gifu University, Gifu, Japan). See section 1.4 for size of stages.

The life cycle of Trichinella species, and in general order Trichocephalida, differs from that of the free-living model C. elegans; differences are mainly recognized in the underlined morphology, biology and physiology of the species. Although much is unknown about Trichinella spp. when compared to the well studied C. elegans, some striking differences include: the stichocyte esophagus which is composed of stacks of cylindrical cells (characteristic for species of order Trichocephalida) rather than a muscular esophagus, lack of phasmids found in nematodes that comprise the Secernentia, and longitudinal rows of bacillary band cells that run the length of the body, the function of which is under debate (Kozek, 2005). Furthermore, the embryologic development of the Dorylaimia species involves anterior positioning of the endodermal precursor by contrast to a posterior positioning in C. elegans (Voronov, 2001). While a dauer stage has not been formally described for Trichinella spp., similarities between the arrested development displayed by muscle larvae and C. elegans dauer larvae have been reported (Winska et al., 2005).

\subsection{Zoonotic Transmission and Clinical disease}

Factors that contribute to $T$. spiralis transmission to humans include improper management practices in swine operations, food handling (preparation) or both (Hui et al., 1994), making trichenollosis one of the most important food-borne, zoonotic diseases caused by parasitic organisms. T. spiralis is the etiological agent of most human infections and deaths caused by trichinellosis globally, although other encapsulated and nonencapsulated species can cause human infections. In addition, persistence in domestic pigs and an unexpected presence in horses, contributes to the importance of $T$. spiralis in causing most human infections (Bolas-Fernandez and Wakelin, 1990; Kapel et al., 1998). Given a life cycle that relies heavily on carnivore or omnivore consumption of infected meat, the importance of horses in zoonotic transmission may reflect exposure to feed containing protein obtained from animal origin. In addition to domestic sources of infection, sylvatic transmission via consumption of wild game is an important source of human infection, but is more likely to involve species in addition to T. spiralis. It was estimated that as many as 11 million people may be infected worldwide with Trichinella spp. (Dupouy-Camet, 2000). While clinical cases have plummeted with education, infections occur under many circumstances including rural, urban and less developed settings. This broad representation may reflect lapses in education, i.e. knowledge of potential sources including meat from horses and wild game, ethnic practices or more exotic culinary preferences. Under-represented groups include those whose religious practices exclude consumption of pork (Dupouy-Camet, 2000). 


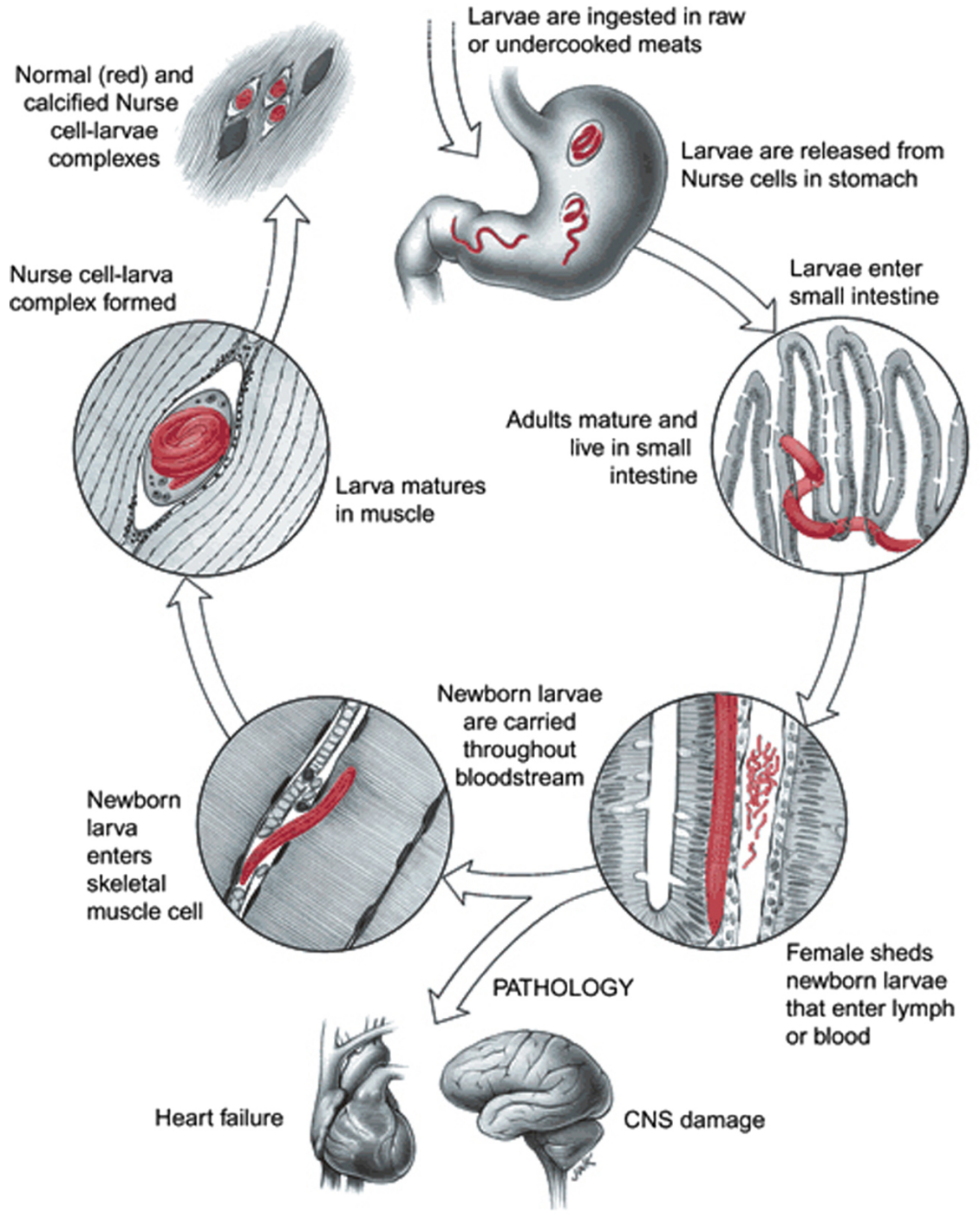

Figure 3. Trichinella spiralis life-cycle. (Photo courtesy of John W. Karapelou.)

Clinical aspects of Trichinellosis are summarized in Figure 4. The symptoms of T. spiralis infection are highly correlated with the stage of infection, i.e., enteral, or muscle phase. The initial symptoms of the enteral phase which starts after eating contaminated meat, include: mild transient diarrhea and nausea (e.g., Kociecka, 1993) due to larval and adult worms invasion of the intestinal mucosa, upper abdominal pain vomiting, malaise, and low-grade fever. These symptoms are similar to many enteral disorders, and therefore the enteral phase of infection is easily misdiagnosed (Compton et al., 1993; Murrell and Bruschi, 1994b). Two to six weeks after infection, the enteral phase is still present but symptoms that correlate with intestinal disease abate, and the signs due to parenteral stages (migratory newborn larvae and muscle infections) appear. These symptoms are usually the first to be clinically detected and include: diffuse myalgia, a paralysis-like state, periorbital and/or facial edema, conjunctivitis, fever, headache, skin rash etc. The duration of the incubation period is related to the number of larvae ingested, which determines the severity of disease (Kefenie and Bero, 1992; Schmitt et al., 1978). Furthermore, host immunity, age, sex and general health of the infected individual are important factors in the outcome of the disease (Kim, 1991; Pawlowski, 1983). Although cardiac muscle does not sustain infection by muscle larvae, transient infection causes severe myocarditis which has been implicated in mortality caused by the infection (Ursell et al., 1984). 


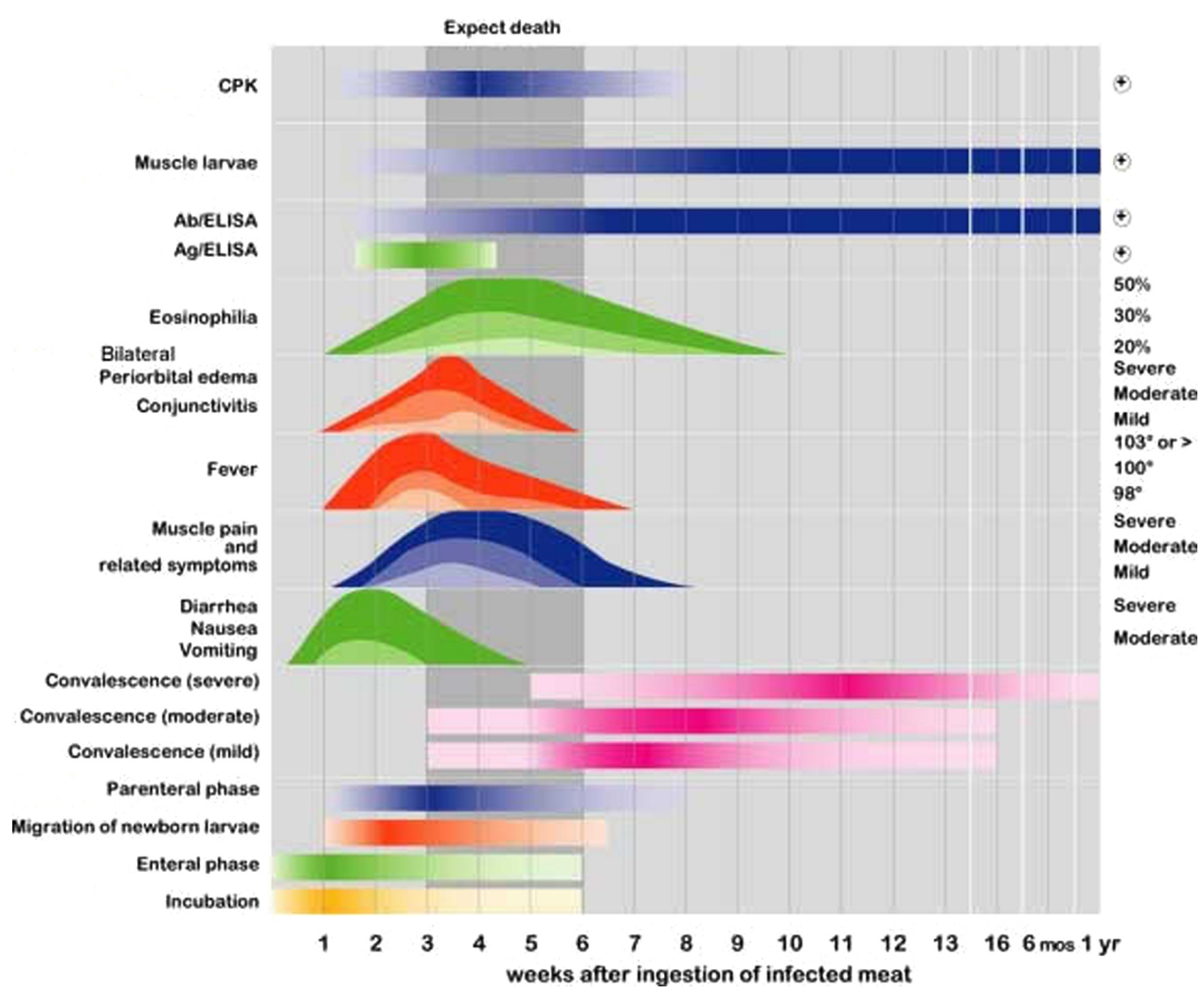

Figure 4. Comprehensive summary of the main clinical signs and symptoms, laboratory findings, and diagnostic test results for patients suffering from mild (light color) to severe (most intense color) clinical trichinellosis. Labels on the left indicate qualitative aspects of the infection, while those on the right give a quantitative assessment of each. The colors are matched to the stage of the infection (shown at the bottom). When the color is faded in and out, that particular qualitative aspect is gradual in onset. The shaded portion (vertical shading between weeks 3 and 6) correlates with the period of infection in which the death of the patient usually occurs if the dose of parasite ingested is high enough to be lethal. Ab, antibody; Ag, antigen. Reprinted with permission from Capó and Despommier (1996).

Pathogenecity of T. spiralis is higher than that of other species due to the higher number of newborn larvae produced by the females (Pozio et al., 1992b) and the more intense immune reaction induced in humans (Bruschi et al., 1999; Gomez Morales et al., 2002).

\section{Molecular and cellular interactions with the host}

Given the medical importance of Trichinella spp. there is need to better understand details of the host-parasite interaction. Investigations have revealed very interesting relationships, some of which will be mentioned here. Trichinella spp. inhabit intracellular niches during both the enteric and muscle phases of the infection. In addition to identifying and invading host cells, the parasite must survive in host tissues of immunocompetent hosts for substantial periods of time. Success here is likely to involve parasite manipulation of both the host cells inhabited and the host immune system. Our current understanding indicates that the molecular and cellular dissection of these interactions will provide unique insight on basic biology of both the host and parasite.

\subsection{Enteric infections}

As one of the largest known intracellular pathogens, T. spiralis is a multi-intracellular parasite of epithelial cells during the intestinal phase of infection. This unusual relationship characterizes the infection by L1 larvae up through the L5 adult (reviewed by Despommier, 1983). Presumably, multi-intracellular intestinal infections also characterize other Trichinella species. Numerous questions arise regarding mechanisms of initiation and maintenance of this multi-intracellular infection. The purpose and benefits of this interaction for the parasite are also unresolved. A significant advance in this regard is the development of an in vitro culture system for the intestinal phase of T. spiralis infection (Gagliardo et al., 2002; ManWarren et al., 1997). This system supports development to the adult stage and offers a valuable tool to answer the foregoing questions. 
Muscle larvae isolated from a previous host will invade monolayers of epithelial cells. This behavior appears to be restricted to epithelial cells, but not all epithelial cells will support invasion (ManWarren et al., 1997). Efficient invasion requires stimulation of muscle larvae with intestinal content or bile. Larvae browse the surface of the monolayer, perhaps sensing for an appropriate ligand, and with the appropriate cell type, invade the monolayer. Invasion involves movement through the monolayer, leading to a trail of dead cells marking the path of the parasite. The cells die in context of membrane disruption, loss of cytoplasmic contact and rupture of organelles (Li et al., 1998). Even in absence of invasion, permeability was altered in epithelial cells as detected with fluorescent tagged small molecules (Butcher et al., 2000). Whether or not this alteration reflects a mechanical perturbation or a more sophisticated interaction with host cells is uncertain, but secretory glycoproteins from the parasite were observed to locate into intra-organellar compartments within these cells. Inhibition of both invasion and in vitro parasite development was accomplished with antibodies against a glycan molecule (tyvelose sugar, see Section 2.4; McVay et al., 2000). This glycan is added to secretory proteins which are synthesized in stichocytes that comprise the esophagus of muscle larvae. A trail of these glycoproteins can be observed along the path of dead epithelial cells destroyed by migrating larvae (ManWarren et al., 1997). Treatment with anti-tyvelose antibodies causes aggregates of cross-linked proteins to form at the cephalic end of larvae. While the aggregates could interfere with sensing by the parasite, monovalent Fab fragments of these antibodies inhibited invasion, also (McVay et al., 1998). Therefore, the glycoproteins recognized might have specific functions in the invasion process. These in vitro results are consistent with the in vivo inhibition of infection conferred by these antibodies (Carlisle et al., 1991), but provide clarifying details not resolved with the in vivo model. While the glycoproteins implicated are quite diverse, progress made on genomics and proteomics of secreted proteins (see sections 3, 4 \& 5) may aid in identifying proteins that warrant investigation here.

Another point addressed with this in vitro system is the response of epithelial cells to infection, but in the absence of other host cells and tissues. Despite the destruction of epithelial cells, co-culture of muscle larvae also induced up-regulation of transcripts for the proinflammatory mediators IL-1 $\beta$ and chemokines IL- 8 and ENA-78 (Li et al., 1998). Whether this expression is induced directly by epithelial cells undergoing damage or by bystander cells remains unclear. It becomes interesting to determine if the effect results from direct interactions with the parasite or signals released from damaged cells. In any case, these results could reflect early responses that attract the influx of immune cells which ultimately lead to a protective immune response. This culture system might provide deeper insight into such responses when queried using expression microarray technologies.

\subsection{Muscle cell infections}

Most available molecular data address interactions during the muscle phase. The intramuscle cell infection induces radical changes in previously, terminally differentiated skeletal muscle cells. An initiation phase of changes is evident by five days or slightly before and is associated with disruption of myofibrils, enlargement and centralization of host muscle nuclei and elevated expression of two host markers, acid phosphatase activity and syndecan-1 (Beiting et al., 2006; Despommier, 1975; Jasmer, 2001; Jasmer et al., 1991). Infection induced-replication of muscle cell DNA approximately coincides with these changes (Jasmer, 1993). The cell cycle reentry leads to accumulation of a $4 \mathrm{~N}$ complement of nuclear DNA, but does not culminate in karyokinesis. This repositioning in apparent G2/M persists for months to years. Muscle gene expression is repressed in association with host cell cycle repositioning. With loss of the muscle differentiation program, a new and still mysterious host phenotype emerges to apparent completeness, inclusive of collagen capsule formation, from 10 to 15 days after muscle cell infection (Polvere et al., 1997). The phenotype as we know it persists from this time onward, which is referred to as the maintenance phase.

The relative roles of host and parasite in regulating specific characteristics of the host cell remain a key question. There is the possibility that maintenance of the abnormal positioning in the cell cycle is regulated in part by the host cell, and repression of muscle gene expression could be mediated by changes in the gene regulatory environment that accompany host cell cycle repositioning (Jasmer, 1993). Nevertheless, some evidence indicates that cell cycle re-entry is parasite induced (Jasmer and Neary, 1994), which identifies one prospective role for the parasite in manipulating its host cell during the initiation phase. Further evidence indicates active parasite regulation of the host cell during the maintenance phase. Nuclear antigens (NA, 79-97 kDa) have been detected in host cell nuclei with antibodies against a T. spiralis glycan (Despommier et al., 1990; Jasmer et al., 1994; discussed in section 2.4), which is added onto secreted proteins of muscle larvae. NA become detectable in host nuclei by 9 days post-infection and persist throughout the maintenance phase. NA colocalize with host chromatin throughout the nucleoplasm and form nuclear complexes, which appear involve both charge and conformation (Yao and Jasmer, 1998). These NA are hypothesized to cause elevated gene expression by the altered host muscle cells and could 
account for at least a doubling in total RNA and protein synthesized in these cells (Yao et al., 1998; Yao and Jasmer, 2001). This predicted role for the parasite in regulating host cell characteristics during the maintenance phase differs from that of cell cycle reentry during the initiation phase, which could indicate involvement of distinct regulatory molecules.

The collagen capsule that envelopes infected cells of encapsulated Trichinella spp. appears to be host derived, yet conveys phylogenetic information that distinguishes major clades within the parasite genus. Debate continues on the origin of the collagen capsule. For instance, collagen gene expression is elevated in infected cells (Polvere et al., 1997), and the collagen capsule forms in muscles of nude mice which are compromised for T lymphocyte production and the inflammation that normally infiltrates infected muscle tissue of immunocompetent mammals. Hence, capsule formation does not appear to depend on the host immune response. Nevertheless, the potential remains for contribution to the collagen capsule from fibroblasts that infiltrate around infected cells (Haehling et al., 1995). Certainly, the maintenance of this feature throughout an evolutionary lineage suggests a function of basic importance which is lacking from nonencapsulated species.

The alterations induced by $T$. spiralis infection in muscle cells may be adaptive for nutrient acquisition, growth, development and/or altered detection by the host immune system. Worthy of note is that the host cell changes documented are related to a species of the encapsulated Trichinella, a group which is inclusive of cold tolerant species. It is possible that some changes in host muscle cells infected with $T$. spiralis reflect physical antecedants that led to adaptation of more extreme cold tolerance found in the other encapsulated species. While less well characterized, host cell changes induced by nonencapsulated species are less extreme (Gustowska et al., 1980; Miroshnichenko, 1978).

\subsection{Immunological interactions}

The actual value of vaccines to prevention of trichinellosis in humans is unclear, given that prevalence of infection in domestic swine is generally low when good management is practiced. Nevertheless, details on basic interactions between Trichinella spp. and the host immune system offer lessons of value in a more general sense, a few examples of which will be mentioned here. In contrast to the muscle phase of infection, worms in the intestinal phase can be expelled within weeks of a primary infection. Experimental systems utilizing T. spiralis intestinal infections have generated valuable information on immunopathophysiology of mammalian gut (Khan and Collins, 2004) and basic insights into mechanisms of host immunity against gut pathogens (Finkelman et al., 2004). While not fully understood, the immune mechanism responsible for expulsion involves several components of a $\mathrm{T}$ helper 2 (Th2) based response, including CD4+ T lymphocytes, mast cells, associated Th2 cytokines and Th2 cellular signalling pathways. Despite accompanying numerous gastrointestinal (GI) nematode infections, host mastositosis has a demonstrated a role in immunity against only a limited number of these pathogens, including $T$. spiralis. Research using the $T$. spiralis model has revealed much regarding regulation of mast cell responses and cellular mechanisms of immunity conferred by mastositosis in this infection (Pennock and Grencis, 2006).

Extensive analysis of host immune responses has also led to the important realization that expulsion of gastrointestinal nematodes can involve antibody-independent mechanisms (Finkelman et al., 2004). Those mechanisms currently appear to involve regulation by the Th2 cytokine IL-13 acting on host cells lining mucosal surfaces, with goblet cells receiving greatest scrutiny. The secreted goblet cell protein, RELM- $\beta$, has been implicated in having novel anthelmintic properties that may antagonize neurosensory systems of multiple nematodes in vivo, including T. spiralis (Artis et al., 2004). Other proteins found to be specifically upregulated at intestinal mucosal surfaces during T. spiralis infection were intelectins and small proline rich proteins (Knight et al., 2004), which may have roles in the expulsion process. A key implication of these advances is that CD4+ Th2 responses, and IL-13 in particular, have a key role in vaccine strategies against GI nematodes, independent of antibody-based mechanisms. This view could have radical consequences for the kind of antigens that will comprise successful vaccines against GI nematodes.

Increasingly interesting phenomena are associated with the regulation of immune responses during the muscle phase of the infection. This information has potential benefit since the most serious clinical signs are associated with inflammation induced at this point of infection. One involves a markedly lower level of muscle inflammation induced by T. pseudospiralis as compared to T. spiralis (Stewart et al., 1985). Coinfection with T. pseudospiralis also leads to lower inflammation around $T$. spiralis infected cells, suggesting active modulation by $T$. pseudospiralis and parasite factors that remain to be identified. Nevertheless, the inflammation that is induced by $T$. spiralis was shown to be limited by host IL-10 early in infection (Beiting et al., 2004). Despite the persistent infection of muscle cells, the inflammation surrounding $T$. spiralis infected cells substantially subsides over time, suggesting regulation 
of the initial response, but in an IL-10 independent manner. The role $T$. spiralis plays in these dynamic changes are of basic interest to determine. An interesting point is that the inflammatory response described has no established significance to protection against $T$. spiralis muscle larvae. Hence, the sequential repression of inflammation has most obvious significance for the well-being of the parasitized host. One implication of this scenario is the prolongation of survival for infected hosts, which could help stabilize this parasite reservoir for more continuous transmission in nature.

Deciphering immune regulatory mechanisms that are activated during infections by Trichinella spp. is of interest from a more general perspective. One case in point is the observation that coinfection with $T$. spiralis was associated with more rapid recovery from clinical influenza infections in mice (Furze et al., 2006). This effect was associated with the early phase of $T$. spiralis infection, which would have included migration of larvae through tissues inclusive of lung, and occurred in an IL-10 independent manner. Since the effect was achieved by an external treatment, underlying principles of mechanisms involved might have application in a clinical setting for treating influenza. These observations add to increasing evidence that immune regulatory mechanisms activated during helminth infections have potential for clinical applications (Harnett et al., 2004; Summers et al., 2005). The latter reference addresses the use of infections by the swine parasite Trichuris suis, another Clade I parasite of the Nematoda, to treat inflammatory bowel diseases in humans. Rationale for this treatment is that $T$. suis infection is largely transient in humans, but sufficient for immune stimulation and apparent suppression of pathological immune responses.

\subsection{Parasite molecules that interact with the host}

In addition to classic antigens, which will not be discussed, there is much interest in molecules produced by Trichinella spp. that modulate host functions. A major focus has been on excretory-secretory (ES) products obtained from larvae that are released from muscle tissue by digestion with pepsin and HCl. ES products are viewed as likely candidates for a role in such interactions. A number of ES proteins have been identified from this stage (see also section 3.3), including a putative DNase II and a serine protease (Romaris et al., 2002; Su et al., 1991; Vassilatis et al., 1992). Nevertheless, it remains uncertain if the known ES proteins from muscle larvae function during the intracellular infection of skeletal muscle cells, or if the expression during this time is in preparation for the subsequent intestinal phase of infection (Jasmer and Neary, 1994). Function of the putative DNase and serine protease could potentially benefit infections in either location. However when ectopically expressed in muscle cells under in vitro conditions, the putative DNase II protein did not prevent muscle gene expression (Jasmer and Kwak, 2006), although some toxic effects of this protein complicated interpretation of those results. Bile treatment, which mimics conditions in the small intestine, caused elevated production of ES products by isolated muscle larvae (Smith et al., 2000), suggesting that at least some ES products have roles during the intestinal phase. Two interesting groups of activities discovered from the latter experiments involve external kinases and nucleotide metabolizing enzymes (Gounaris and Selkirk, 2005; Smith et al., 2000). Each of these activities have potential for modulating multiple host functions. Forthcoming and already cloned genes for these enzymes should help to clarify when during the life cycle these proteins have functional significance, which is crucial information to determine biological function.

Nematodes can produce complex carbohydrates (glycans) that may have key functions in interactions with the host immune system. T. spiralis produces an unusual glycan which is added to multiple ES proteins of muscle larvae. The glycan has a tri- and tetrantenary structures with a terminal tyvelose, which is a dideoxy arabinohexose (Reason et al., 1994; Wisnewski et al., 1993). The structure conferred by the tyvelose moiety creates an antibody epitope, which occurs on multiple ES proteins of T. spiralis muscle larvae. From an immunological perspective, antibodies against his epitope can protect against intestinal invasion by the parasite (Ellis et al., 1994). From a different angle, antibodies against this epitope bind to nuclei of host muscle cells infected by muscle larvae (nuclear antigens described above). While a proposed role for the glycan in this interaction is not yet warranted, the fortuitous occurrence of the glycan on nuclear antigens facilitated the generation of significant information on these proteins. The glycan under discussion appears to be restricted to expression in muscle larvae. Glycans from other life cycle stages have not been investigated, but they may have equally interesting properties. Of course since the primary sequence of glycans is not encoded by nucleic acids, serious obstacles exist for a glycomics approach with limited biological material available from some of these stages.

\section{Use of molecular biology in Trichinella}

Molecular approaches have been used effectively for advancing methods to diagnose infections and distinguish species (strains or genotypes) for epidemiological purposes. Although a number of protein coding genes 
have been cloned, primarily from $T$. spiralis, clarification on roles of these proteins in the biology of the parasite or interactions with the host are only beginning to emerge.

\subsection{Diagnostics}

T. spiralis is the most important species in domestic swine for zoontic transmission. Two primary methods are used to test swine for this infection. The preferred method for diagnosing infected swine is by digesting meat samples (e.g., diaphragm, masseters, tongue or other muscles) with HCL-pepsin (e.g., Ribicich et al., 2001) and then microscopic inspection for larvae. While somewhat cumbersome, sensitivity of this method is relatively uniform throughout an infection. Enzyme-linked immunosorbent assays (ELISA) are an alternative method that provides for relatively rapid detection of $T$. spiralis infection by serology. One advantage is that ELISA can detect infection prior to slaughtering. As one approach serum samples are used to detect anti-T. spiralis antibodies against $T$. spiralis exscretory/secretory (ES) products, which requires the parasite for production. An alternative approach was use of the tyvelose-based epitope (see section 2.4), since it it appears to be a major antigen recognized during infection (Denkers et al., 1990). Structural information on the glycan led to the synthesis of a glycan for use in ELISA (Wisnewski et al., 1997). However, sensitivity of ELISA assay can be lower early in infection (Gamble, 1998). Variability in host responses introduces an additional concern, given that the goal is to prevent infected pork or horse meat from entering the market. Nevertheless, the ELISA is a specific and robust method which is recommended for surveillance programs that monitor for transmission of $T$. spiralis within swine herds.

There are several tests available to diagnose trichichinellosis in humans. Muscle biopsy is used to directly observe muscle larvae for unequivocal diagnosis. Biopsies can be evaluated by several methods involving microscopy: 1) pressing tissue samples between 2 slides (Murrell and Bruschi, 1994a; Pawlowski, 1983) for detection of muscle larvae in tissue; 2) digesting a finely minced portion of the biopsy sample in HCL-pepsin and detection of muscle larvae released from tissue (Dordevic, 1991; Murrell and Bruschi, 1994a); and 3) histological examination of stained sections of biopsied muscle (Purkerson and Despommier, 1994). Alternatively, several serologic assays have been used for diagnosing human infections, including indirect immunofluorescence assays (IFA) and ELISAs (Dordevic, 1991; Ivanoska et al., 1989). However, cross-reactivity with other parasites can complicate interpretation of IFAs and ELISAs, and an additional test, such as western blot, is considered useful for differential diagnosis (Roberts et al., 1994; Yera et al., 2003). Serologic diagnosis during the early infection and acute phase is more problematic, with weak reactions complicating interpretation of these tests.

\subsection{Species identification}

Morphologic criteria are insufficient to specifically identify muscle larvae that are in or derived from infected muscle. Since mixed infections can also occur (Pozio et al., 1995; Pozio et al., 1997), identification of single larvae to species can aid in determining the source of infection and the clinical course in humans. Identification of Trichinella species has evolved from earlier methods relying on a combination of DNA typing (Dick, 1983) and isozyme patterns (e.g., Pozio et al., 1992a). RAPD-based analysis was the first PCR-based method (Bandi et al., 1995; Bandi et al., 1993). This method is based on the detection of genetic markers using only a single arbitrary primer and can be used without prior sequence information (Williams et al., 1990). However, reproducibility is an obstacle with RAPD analysis, which also can be very sensitive to DNA quality (Penner et al., 1993). Several other PCR-based assays evaluated specific genomic sequences (Appleyard et al., 1999; Soule et al., 1993; Wu et al., 1998; Zarlenga et al., 1999) and a multiplex method was developed that differentiates all Trichinella spp. (Zarlenga et al., 2001). Other discriminating methods have been described, such as overall length and cleavage fragment length polymorphisms in the 5S rRNA intergenic spacer region (Rombout et al., 2001), and a reverse line blot (RLB) assay (Gubbels et al., 1999; Rijpkema et al., 1995). Several of these methods can be used on single muscle larvae. Molecular approaches have contributed significantly to specific identification of individual Trichinella spp. These and future advances are of great importance for epidemiological and phylogenetic studies.

\subsection{Proteomics}

Proteomics tools are used to analyze excretory and secretory (ES) products in parasites. ES proteins are believed to have roles in formation of the host-parasite complex and inducing changes in the host cells (Kwan-Lim et al., 1989). Early studies involved surface labeling of proteins on three stages of $T$. spiralis with iodine and examination by 1-DE (Clark et al., 1982), or use of 2-DE for identifying ES proteins in infected muscle (Jasmer, 1990), or muscle larvae (Dea-Ayuela et al., 2001; Wu et al., 1999). The attempts resulted in analyzing only few ES proteins in terms of their biological activity, due largely to problems in identifying individual proteins. Furthermore, 
two proteins found in the ES fraction collected from muscle larvae cultivated in vitro lacked a typical N-terminal signal sequence, while secretion appeared to be mediated through the classical ER/Golgi secretory pathway (Kuratli et al., 2001). Later studies used 2-DE and proteomic analysis to identify ES proteins from T. spiralis. PMF data obtained from MALDI-TOF mass spectrometric analysis of ES peptide spots excised from two-dimensional gels was used to confirm the existence of 2 members of a family of nematode-specific proteins that have N-terminal signal peptides (Gare et al., 2004). Expressed sequence tags (ESTs) generated from three life stages of T. spiralis (adult, mature muscle larvae, immature L1 larvae) improved the technical capacity for proteomic research on Trichinella spp. (Mitreva et al., 2005 and section 4). By coupling protein sequence similarity with signal peptide prediction, $345 \mathrm{~T}$. spiralis clusters were identified that had homology with predicted secreted or membrane proteins. The EST clusters supported interpretation of peptide mass fingerprint data obtained from 2DE analysis of muscle larvae ES proteins (Robinson et al., 2005). More recent 2DE electrophoresis of ES proteins was coupled with MALDI-TOF- and LC-MS/MS enabling the most comprehensive identification of peptide spots from T. spiralis performed thus far (Robinson et al., 2005). Identities were assigned to 43 out of 52 ES peptide spots analyzed based on either the PMF data or de novo peptide data derived from LC-MS/MS. Interestingly, the 43 spots represented only 13 different proteins indicating that there are multiple protein isoforms present in the ES, the most prominent of which are a serine protease, the $45-\mathrm{kDa}$ antigen, gp43 and 2 unidentified open reading frames (Robinson and Connolly, 2005).

\section{Previous genomic applications to study Trichinella}

Until recently the approach taken to study $T$. spiralis involved mainly characterization of individual genes of interest. In 2003, a genomic approach was initiated as an antecedent to more complete nuclear genome sequencing (Wylie et al., 2004). The approach involves use of expressed sequence tags (ESTs) obtained from sampling 3 cDNA libraries generated from three life stages of $T$. spiralis: adult worm (AD), mature muscle larvae (ML) and immature L1 larvae (immL1, also known as newborn larvae). The analysis of the 10,130 ESTs identified a conservative estimate of 3,262 unique genes. Based on genomic information from C. elegans (The C. elegans Sequencing Consortium, 1998), this number represents $17 \%(3,262 / 19,552)$ of all $T$. spiralis genes. The GC content for protein coding exons was $39 \%$ versus $43 \%$ for C. elegans. According to this study, $56 \%$ of the T. spiralis EST clusters had homology to proteins from other species, while $44 \%$ were placed in the category of 'novel' proteins. Furthermore, $82 \%$ of the clusters with homology (1592/1942) had homology to C. elegans (or $46 \%$ of all clusters). The most recent meta-analysis of the transcriptome of the Phylum Nematoda (Parkinson et al., 2004) reported similar results (45\%), and expanding the analysis to species beyond nematodes, identified a similar portion of the ESTs sharing homology with the fruit fly Drosophila melanogaster. Hence, ESTs common to T. spiralis and C. elegans are not necessarily specific to nematodes but may be conserved among diverse taxonomic groups of invertebrates. $C$. elegans is often thought of, and therefore used as, a protopypical nematode because of its usefulness to serve as a model to study biological processes. However, the results from the more extensive single-species analysis (Mitreva et al., 2004) and more broad Phylum-related analysis (Parkinson et al., 2004) highlight the great phylogenetic distance of $T$. spiralis from other nematodes, which makes the extrapolation from the biology of $C$. elegans to $T$. spiralis challenging. However, comparative genomic approaches using both nematodes may be useful to identify molecular features shared between these two widely disparate species that reflect ancestral features found in many nematodes. Furthermore, the authors segregated the identified genes in multiple biological dimensions including functional, developmental and phylogenetic categories. Nematode genes can now be cross-referenced to gain insight on higher order associations. Observations agreed with and extended information on previously described genes and gene families, providing expectations that information on newly discovered $T$. spiralis genes will have similar value. The $T$. spiralis data identified sets of predicted proteins which may define differences in metabolism and molecular interactions that exist among the T. spiralis stages investigated. Evidence of substantial gene families in relation to previously identified antigen genes was especially instructive, as was elucidation of numerous and diverse predicted proteinase genes. The dataset is potentially very useful for proteomics methods (as described in section 3.3) to identify parasite proteins that occur in specific compartments, such as host muscle nuclei and parasite excretory-secretory products and the external cuticular surface. The observations made provide strong rationale to gain a more complete assessment of genes expressed among T. spiralis stages. From a phylogenetic perspective, adenophorean orders that comprise clade I, such as the Trichocephalida (Trichinella, Trichuris, Capillaria), Mermithida, Dorylaimida, and Mononchida, remain largely unexplored territory for genomic studies. This initial analysis of expressed genes in T. spiralis confirms an ancient divergence of clade I nematodes from those of other clades and provides an entry point toward a deep understanding of the phylum Nematoda at the molecular level. These findings have stimulated a nuclear genome sequencing project for $T$. spiralis with this goal in mind, discussed in section 5 . 
For many nematode genes, trans-splicing of a short leader sequence to the $5^{\prime}$ end of the mRNA is a feature of transcript maturation. The most common trans-splice leader is SL1, the sequence of which is highly conserved across the phylum (Blaxter and Liu, 1996; Conrad et al., 1991; Krause and Hirsh, 1987). It is estimated that 80\% of Ascaris suum transcripts (Nilsen, 1993), 70\% of C. elegans transcripts (Blumenthal and Steward, 1997), and 60\% of Globodera rostochiensis transcripts are SL1 trans-spliced (Ling Qin, personal communication). While the extent to which each nematode species uses SL1 is unknown, the Parasitic Nematode Sequencing group at the Washington University Genome Sequencing Center has made SL1-PCR libraries from 18 nematode species to date (www.nematode.net; Wylie et al., 2004). While these libraries are inclusive of one for T. spiralis, difficulties were encountered in making this library. For instance, utilizing the standard protocol for generating SL1-based libraries, the $T$. spiralis SL1-based library produced a much lower passing rate than other species. This can imply that either the SL1 sequence is more divergent in $T$. spiralis than in other nematodes, making capture of SL1-modified mRNAs difficult, or very few genes (if any) are preceded by the most common nematode SL1 sequence. Currently, there is no direct evidence for splice leader addition to mRNAs from $T$. spiralis or other clade I nematodes. Genome sequencing may provide information to distinguish these possibilities. Because spliced leader addition is also associated with the organization and expression of C. elegans genes in operons (Blumenthal and Gleason, 2003), the status of spliced leader additions in $T$. spiralis and other clade I nematodes should be clarified.

Mitochondrial DNAs (mtDNAs) vary extensively in size and gene content across diverse eukaryotic groups, while those of animals (Metazoa), however are relatively more uniform (Lang et al., 1999). As of May 2006, there are 13 nematode mtDNA sequences in the GenBank (http://www.ncbi.nlm.nih.gov/entrez/query.fcgi?db=Genome $\& \mathrm{cmd}=$ Search\&dopt=DocSum\&term=txid6231[Organism:exp]. Although nematode mitochondrial genome sequence data available thus far conforms more or less with current generalizations concerning metazoan mtDNAs, the genomes do contain some unique features and common characteristics. These include 12 protein-coding genes (lacking the atp 8 gene, except for Trichinella spiralis in which it is also encoded), the lack of either a DHU or TYC arm in the tRNA secondary structure and apparent unidirectional transcription, where all genes occur on the same strand (see Hu et al., 2003 for details), with the exception of T. spiralis (Lavrov and Brown, 2001) and Xiphinema americanum (He et al., unpublished) where some genes would be transcribed from the opposite strand. Convergent evolution (not derived from a common ancestry) of gene rearrangement is generally known to be rare (Lavrov et al., 2004). Therefore, comparative analysis of the mitochondrial genome information (e.g., gene arrangement, nucleotide and amino acid sequences) has often been used as a reliable tool for resolving the phylogenetic relationships in a large number of diverse animal groups with ancient evolutionary origins (Boore and Brown, 2000; Smith et al., 1993; Larget et al., 2005). The mitochondrial genome of $T$. spiralis revealed that its organization more closely resembles that of the coelomate metazoans than that of its presumed closest relatives, the secernentean nematodes (Lavrov and Brown, 2001). Furthermore, T. spiralis is the only nematode species known in which mtDNA includes a putative atp8 gene (as discussed above), bringing the total of recognized T. spiralis mtDNA genes to 37 genes, which is typical of most metazoan mtDNA (Lavrov and Brown, 2001).

\section{Current genome sequencing project for Trichinella spiralis}

In a hunt for a representative basal or outgroup nematode, The National Human Genome Research Institute (NHGRI) called for proposals for species that represent a position on the evolutionary timeline marked by important changes in animal anatomy, physiology, development or behavior. In addition, the T. spiralis genome sequence was expected to contribute in several ways: i) to provide a better understanding of evolutionary biology by identifying gene loss or gain across the phylum Nematoda and clarify evolution of genome architecture (synteny, operons); ii) help identify RNA genes and regulatory regions; and iii) better define proteins involved in nematode parasitism that impact health and disease and are relevant to both host-parasite relationships and basic biological processes. In 2004, the NHGRI announced that the Large-Scale Sequencing Research Network received financial support for sequencing the genome of the adenophorean nematode of clade I, Trichinella spiralis.

Washington University's Genome Sequencing Center (GSC) was assigned to sequence the T. spiralis genome. The sequencing plan called for BAC fingerprint map, BAC end sequencing, 8-fold sequence coverage in plasmids, end sequence of a fosmid library at 0.3 -fold coverage, followed by two rounds of directed sequence improvement (pre-finishing). The genome sequence project is in progress and as of April 2006, there were 4,168,619 traces in the NCBI trace archive, of which 3,940,023 are WGS sequences, 29,360 shotgun reads, and 199,236 fosmid end sequences.

The PCAP package (Huang et al., 2006) was used to perform an initial assembly (http://genome.wustl. edu/genome.cgi?GENOME=Trichinella\%20spiralis). $96 \%(3,389,303 / 3,534,683)$ of the reads were placed in the 
assembly with $97 \%(55,472,619$ / 56,779,425) of the sequences having output contig quality scores of $\geq Q 20$. The assembled genome size $(56.8 \mathrm{Mb})$ deviated significantly from earlier published estimates (Searcy and MacInnis, 1970) but was close to recent genome size estimate of $1 \mathrm{C}=71.3 \pm 1.2 \mathrm{Mb}$ based on flow sorted nuclei, stained with PI (Spencer Johnston, unpublished). Preliminary analysis using Caenorhabditis spp. genes (C. elegans, C. brigssae, C. remanei) and all parasitic nematode originated ESTs (September 2006) identified 6,845 unique loci within the 6,262 supercontigs of the $T$. spiralis assembly (at least 80 bits for an match to be consider as a significant). Of these, $38 \%(2,575 / 6,845)$ got matched by free-living and parasitic nematodes, and $41 \%(2,813 / 6,845)$ loci were identified only by the available $T$. spiralis ESTs (Mitreva et al., 2004). Furthermore, $21 \%(1,457 / 6,845)$ of the loci were identified only by parasitic nematode originated sequences i.e. putative parasitism genes. Several nematode genomes are completed or underway (Table 1), however the majority of the available sequencing data from parasitic nematodes are ESTs (>375,000 from 40 species; http://www.ncbi.nlm.nih.gov/entrez/query.fcgi), therefore we used the parasitic nematode ESTs to identify putative parasitism genes. More information on the number of genes that are T. spiralis, lineage or parasitism specific, will be revealed after the $T$. spiralis gene set becomes available and compared to the nematode genomes that are completed or underway (Table 1).

Table 1. Nematode taxa for which a genome sequencing project is underway

\begin{tabular}{|c|c|c|c|c|c|}
\hline Spices & Clade & Tropic ecology & Status $^{\mathrm{a}}$ & \begin{tabular}{|c|} 
Size of \\
genome $(\mathrm{Mb})$
\end{tabular} & Funding \\
\hline \multicolumn{6}{|l|}{ Draft genome (6-8x coverag) } \\
\hline Caenorhabditis elegans & $\mathrm{V}$ & Bacteriovore & $\mathrm{C}$ & 100.2 & $\begin{array}{l}\text { NHGRI and } \\
\text { MRC }\end{array}$ \\
\hline Caenorhabditis briggsae & $\mathrm{V}$ & Bacteriovore & $\mathrm{C}$ & 105 & $\begin{array}{c}\text { NHGRI and } \\
\text { Wellcome Trust }\end{array}$ \\
\hline Caenorhabditis remanei & $\mathrm{V}$ & Bacteriovore & $\mathrm{C}$ & 131 & NHGRI \\
\hline Caenorhadbitis japonica & $\mathrm{V}$ & Bacteriovore & $\mathrm{P}$ & - & NHGRI \\
\hline Caenorhabditis sp. c.f. pB2801 & $\mathrm{V}$ & Bacteriovore & $\mathrm{P}$ & 150 & NHGRI \\
\hline Pristionchus pacificus & $\mathrm{V}$ & Omnivore & $\mathrm{P}$ & 170.2 & NHGRI \\
\hline Heterorhabditis bacteriophora & $\mathrm{V}$ & $\begin{array}{c}\text { insect-associated } \\
\text { bacteriovorre }\end{array}$ & $\mathrm{P}$ & $\sim 110$ & NHGRI \\
\hline Brugia malayi & III & Vertebrate parasite & $\mathrm{C}$ & $\sim 100$ & NIAID \\
\hline Haemonchus contortus & $\mathrm{V}$ & Vertebrate parasite & $\mathrm{P}$ & $\sim 55$ & Wellcome Trust \\
\hline Meloidogyne hapla & IV & Plant parasite & $\mathrm{P}$ & 62.5 & NSF/USDA \\
\hline Meloidogyne incognita & IV & Plant parasite & $\mathrm{P}$ & $\sim 50$ & Genoscope \\
\hline Trichinella spiralis & $\mathrm{I}$ & Vertebrate parasite & $\mathrm{P}$ & 71.3 & NHGRI \\
\hline \multicolumn{6}{|l|}{ Low covergae of the genome $(1-3 x)$} \\
\hline Ancylostoma caninum & $\mathrm{V}$ & Vertebrate pararsite & $\mathrm{C}$ & $\sim 50$ & NAIAD \\
\hline Pristionchus naupasi & & Omnivore & $\mathrm{P}$ & 500 & Max Planck \\
\hline Pristionchus entomophagous & & Omnivore & $\mathrm{P}$ & 160 & Max Planck \\
\hline Ascaris suum & III & Vertebrate parasite & $\mathrm{C}$ & $\sim 300$ & NAIAD \\
\hline Heterodera glycines & IV & Plant parasite & $\mathrm{C}$ & $\sim 50$ & NSF/USDA \\
\hline
\end{tabular}

\section{Acknowledgements}

This work was in part supported by grant from the National Human Genome Research Institute (U54 HG003079), principal investigator, Richard K. Wilson. 


\section{References}

Appleyard, G.D., Zarlenga, D., Pozio, E., and Gajadhar, A.A. (1999). Differentiation of Trichinella genotypes by polymerase chain reaction using sequence-specific primers. J. Parasitol. 85, 556-559. Abstract Article

Artis, D., Wang, M.L., Keilbaugh, S.A., He, W., Brenes, M., Swain, G.P., Knight, P.A., Donaldson, D.D., Lazar, M.A., Miller, H.R., et al. (2004). RELMbeta/FIZZ2 is a goblet cell-specific immune-effector molecule in the gastrointestinal tract. Proc. Natl. Acad. Sci. U.S.A. 101, 13596-13600. Abstract Article

Bandi, C., La Rosa, G., Bardin, M.G., Damiani, G., Comincini, S., Tasciotti, L., and Pozio, E. (1995). Random amplified polymorphic DNA fingerprints of the eight taxa of Trichinella and their comparison with allozyme analysis. Parasitology 110, 401-407. Abstract

Bandi, C., La Rosa, G., Comincini, S., Damiani, G., and Pozio, E. (1993). Random amplified polymorphic DNA technique for the identification of Trichinella species. Parasitology 107, 419-424. Abstract

Beiting, D.P., Bliss, S.K., Schlafer, D.H., Roberts, V.L., and Appleton, J.A. (2004). Interleukin-10 Limits Local and Body Cavity Inflammation during Infection with Muscle-Stage Trichinella spiralis. Infect. Immun. 72, 3129-3137. Abstract Article

Beiting, D.P., Park, P.W., and Appleton, J.A. (2006). Synthesis of syndecan-1 by skeletal muscle cells is an early response to infection with Trichinella spiralis but is not essential for nurse cell development. Infect. Immun. 74, 1941-1943. Abstract Article

Blaxter, M. (1998). Caenorhabditis elegans is a nematode. Science 282, 2041-2046. Abstract Article

Blaxter, M., and Liu, L. (1996). Nematode spliced leaders--ubiquity, evolution and utility. Int. J. Parasitol. 26, 1025-1033. Abstract Article

Blaxter, M.L., De Ley, P., Garey, J.R., Liu, L.X., Scheldeman, P., Vierstraete, A., Vanfleteren, J.R., Mackey, L.Y., Dorris, M., Frisse, L.M., et al. (1998). A molecular evolutionary framework for the phylum Nematoda. Nature 392, 71-75. Abstract Article

Blumenthal, T., and Gleason, K.S. (2003). Caenorhabditis elegans operons: form and function. Nat. Rev. Genet. 4, 112-120. Abstract Article

Blumenthal, T., and Steward, K. (1997). RNA processing and gene structure, In C. elegans, D.L. Riddle, T. Blumenthal, B.J. Meyer, and J.R. Priess, eds. (Plainview: Cold Spring Harbor Laboratory Press), pp. 117-145.

Bolas-Fernandez, F., and Wakelin, D. (1990). Infectivity, antigenicity and host responses to isolates of the genus Trichinella. Parasitology 100, 491-497. Abstract

Boore, J.L., and Brown, W.M. (2000). Mitochondrial Genomes of Galathealinum, Helobdella, and Platynereis: Sequence and Gene Arrangement Comparisons Indicate that Pogonophora Is Not a Phylum and Annelida and Arthropoda Are Not Sister Taxa. Mol. Biol. Evol. 17, 87-106. Abstract

Bruschi, F., Pozio, E., Watanabe, N., Gomez-Morales, M.A., Ito, M., Huang, Y., and Binaghi, R. (1999). Anaphylactic response to parasite antigens: IgE and IgG1 independently induce death in Trichinella-infected mice. Int. Arch. Allergy Immunol. 119, 291-296. Abstract Article

Butcher, B.A., Gagliardo, L.F., ManWarren, T., and Appleton, J.A. (2000). Larvae-induced plasma membrane wounds and glycoprotein deposition are insufficient for Trichinella spiralis invasion of epithelial cells. Mol. Biochem. Parasitol. 107, 207-218. Abstract Article

Capó, V., and Despommier, D. (1996). Clinical aspects of Infection with Trichinella ssp. Clin. Microbiol. Rev. 9, 47-54. Abstract

Carlisle, M.S., McGregor, D.D., and Appleton, J.A. (1991). The role of the antibody Fc region in rapid expulsion of Trichinella spiralis in suckling rats. Immunology $74,552-558$. Abstract 
Clark, N.W., Philipp, M., and Parkhouse, R.M. (1982). Non-covalent interactions result in aggregation of surface antigens of the parasitic nematode Trichinella spiralis. Biochem. J. 206, 27-32. Abstract

Compton, S.J., Celum, C.L., Lee, C., Thompson, D., Sumi, S.M., Fritsche, T.R., and Coombs, R.W. (1993). Trichinosis with ventilatory failure and persistent myocarditis. Clin. Infect. Dis. 16, 500-504. Abstract

Conrad, R., Thomas, J., Spieth, J., and Blumenthal, T. (1991). Insertion of part of an intron into the $5^{\prime}$ untranslated region of a Caenorhabditis elegans gene converts it into a trans-spliced gene. Mol. Cell. Biol. 11, $1921-1926$. Abstract

Cuperlovic, K., Djordjevic, M., and Pavlovic, S. (2005). Re-emergence of trichinellosis in southeastern Europe due to political and economic changes. Vet. Parasitol. 132, 159-166. Abstract Article

Dea-Ayuela, M.A., Ubeira, F.M., Pitarch, A., Gil, C., Martinez-Fernandez, A.R., and Bolas, F. (2001). A comparison of antigenic peptides in muscle larvae of several Trichinella species by two-dimensional western-blot analysis with monoclonal antibodies. Parasite 8, S117-S119. Abstract

Denkers, E.Y., Wassom, D.L., and Hayes, C.E. (1990). Characterization of Trichinella spiralis antigens sharing an immunodominant, carbohydrate-associated determinant distinct from phosphorylcholine. Mol. Biochem. Parasitol. 41, 241-249. Abstract Article

Despommier, D. (1975). Adaptive changes in muscle fibers infected with Trichinella spiralis. Am. J. Pathol. 78, 477-496. Abstract

Despommier, D.D. (1983). Biology, In Trichinella and trichinosis, W.C. Campbell, ed. (New York: Plenum Press), pp. 75-151.

Despommier, D.D., Gold, A.M., Buck, S.W., Capo, V., and Silberstein, D. (1990). Trichinella spiralis: secreted antigen of the infective L1 larva localizes to the cytoplasm and nucleoplasm of infected host cells. Exp. Parasitol. 71, 27-38. Abstract Article

Dick, T.A. (1983). Species and intraspecific variations in Trichinella and Trichinellosis. In (New York and London: Plenum Press), pp. 31-73.

Dordevic, M. (1991). Detection of Trichinella by various methods in Yugoslavia. Southeast Asian J. Trop. Med. Public Health 22, 326-328. Abstract

Dupouy-Camet, J. (2000). Trichinellosis: a worldwide zoonosis. Vet. Parasitol. 93, 191-200. Abstract Article

Ellis, L.A., Reason, A.J., Morris, H.R., Dell, A., Iglesias, R., Ubeira, F.M., and Appleton, J.A. (1994). Glycans as targets for monoclonal antibodies that protect rats against Trichinella spiralis. Glycobiology 4, 585-592. Abstract

Finkelman, F.D., Shea-Donohue, T., Morris, S.C., Gildea, L., Strait, R., Madden, K.B., Schopf, L., and Urban, J.F. J. (2004). Interleukin-4- and interleukin-13-mediated host protection against intestinal nematode parasites. Immunol. Rev. 201, 139-155. Abstract Article

Flisser, A., Velasco-Villa, A., Martinez-Campos, C., Gonzalez-Dominguez, F., Briseno-Garcia, B., Garcia-Suarez, R., Caballero-Servin, A., Hernandez-Monroy, I., Garcia-Lozano, H., Gutierrez-Cogco, L., et al. (2002). Infectious diseases in Mexico. A survey from 1995-2000. Arch. Med. Res. 33, 343-350. Abstract Article

Furze, R.C., Hussell, T., and Selkirk, M.E. (2006). Amelioration of Influenza-Induced Pathology in Mice by Coinfection with Trichinella spiralis. Infect. Immun. 74, 1924-1932. Abstract Article

Gagliardo, L.F., McVay, C.S., and Appleton, J.A. (2002). Molting, ecdysis, and reproduction of Trichinella spiralis are supported in vitro by intestinal epithelial cells. Infect. Immun. 70, 1853-1859. Abstract Article

Gamble, H.R. (1998). Sensitivity of artificial digestion and enzyme immunoassay methods of inspection for trichinae in pigs. J. Food Prot. 61, 339-343. Abstract 
Gare, D., Boyd, J., and Connolly, B. (2004). Developmental regulation and secretion of nematode-specific cysteine-glycine domain proteins in Trichinella spiralis. Mol. Biochem. Parasitol. 134, 257-266. Abstract Article

Gomez Morales, M.A., Mele, R., Sanchez, M., Sacchini, D., De Giacomo, M., and Pozio, E. (2002). Increased CD8-T-cell expression and a type 2 cytokine pattern during the muscular phase of Trichinella infection in humans. Infect. Immun. 70, 233-239. Abstract Article

Gounaris, K., and Selkirk, M.E. (2005). Parasite nucleotide-metabolizing enzymes and host purinergic signalling. Trends Parasitol. 21, 17-21. Abstract Article

Gubbels, J.M., de Vos, A.P., van der Weide, M., Viseras, J., Schouls, L.M., de Vries, E., and Jongejan, F. (1999). Simultaneous Detection of Bovine Theileria and Babesia Species by Reverse Line Blot Hybridization. J. Clin. Microbiol. 37, 1782-1789. Abstract

Gustowska, L., Gabryel, P., Blotna-Filipiak, M., and Rauhut, W. (1980). Pathomorphology of rat muscle tissue in the course of Trichinella pseudospiralis infection. Wiad. Parazytol. 26, 621-628. Abstract

Haehling, E., Niederkorn, J.Y., and Stewart, G.L. (1995). Trichinella spiralis and Trichinella pseudospiralis induce collagen synthesis by host fibroblasts in vitro and in vivo. Int. J. Parasitol. 25, 1393-1400. Abstract Article

Harnett, W., McInnes, I.B., and Harnett, M.M. (2004). ES-62, a filarial nematode-derived immunomodulator with anti-inflammatory potential. Immunol. Lett. 94, 27-33. Abstract Article

Hu, M., Chilton, N.B., and Gasser, R.B. (2003). The mitochondrial genome of Strongyloides stercoralis (Nematoda) - idiosyncratic gene order and evolutionary implications. Int. J. Parasitol. 33, 1393-1408. Abstract Article

Huang, X., Yang, S.-P., Chinwalla, A.T., Hillier, L.W., Minx, P., Mardis, E.R., and Wilson, R.K. (2006). Application of a superword array in genome assembly. Nucleic Acids Res. 34, 201-205. Abstract Article

Hui, Y.H., Gorham, J.R., Murrell, K.D., and Cliver, D.O. (1994). Foodborn disease handbook, In Disease caused by viruses, parasites and fungi. M. Dekker, ed. (New York), pp. 1-682.

Ivanoska, D., Cuperlovic, K., Gamble, H.R., and Murrell, K.D. (1989). Comparative efficacy of antigen and antibody detection tests for human trichinellosis. J. Parasitol. 75, 38-41. Abstract Article

Jasmer, D.P. (1990). Trichinella spiralis: altered expression of muscle proteins in trichinosis. Exp. Parasitol. 70, 452-465. Abstract Article

Jasmer, D.P. (1993). Trichinella spiralis infected skeletal muscle cells: arrest in G2/M is associated with the loss of muscle gene expression. J. Cell. Biol. 121, 785-793. Abstract

Jasmer, D.P. (2001). Genetic reprogramming of mammalian skeletal muscle cells in trichinellosis., In Parasitic nematodes: Molecular biology, biochemistry and immunology, M.W. Kennedy, and W. Harnett, eds. (CAB International).

Jasmer, D.P., Bohnet, S., and Prieur, D.J. (1991). Trichinella spp.: Differential expression of acid phosphatase and myofibrillar proteins in infected muscle cells. Exp. Parasitol. 72, 321-331. Abstract Article

Jasmer, D.P., and Kwak, D. (2006). Differentiation and fusion of skeletal muscle cells expressing the p43 protein from Trichinella spiralis muscle larvae. Exp. Parasitol. 112, 67-75. Abstract Article

Jasmer, D.P., and Neary, S.M. (1994). Trichinella spiralis: Inhibition of muscle larva growth and development is associated with a delay in expression of infected skeletal muscle characteristics. Exp. Parasitol. 78, 317-325. Abstract Article

Jasmer, D.P., Yao, S., Vassilatis, D.K., Despommier, D., and Neary, S.M. (1994). Failure to detect Trichinella spiralis $\mathrm{p} 43$ in isolated host nuclei and in irradiated larvae of infected muscle cells which express the infected cell phenotype. Mol. Biochem. Parasitol. 67, 225-235. Abstract Article 
Kapel, C.M. O., Webster, P., Lind, P., Pozio, E., Henriksen, S.A., Murrell, K.D., and Nansen, P. (1998). Trichinella spiralis, T. britovi, and T. nativa?: infectivity, larval distribution in muscle, and antibody response after experimental infection of pigs. Parasitol. Res. 84, 264-271. Abstract Article

Katz M, D.D., Gwadz R. (1989). Parasitic Diseases, Second edition edn (New York: Springer Verlag).

Kefenie, H., and Bero, G. (1992). Trichinosis from wild boar meat in Gojjam, north-west Ethiopia. Trop. Geogr. Med. 44, 278-280. Abstract

Khan, W.I., and Collins, S.M. (2004). Immune-mediated alteration in gut physiology and its role in host defence in nematode infection. Parasite Immunol. 26, 319-326. Abstract Article

Kim, C.W. (1991). The significance of changing trends in trichinellosis. Southeast Asian J. Trop. Med. Public Health 22 Suppl, 316-320. Abstract

Knight, P.A., Pemberton, A.D., Robertson, K.A., Roy, D.J., Wright, S.H., and Miller, H.R. (2004). Expression profiling reveals novel innate and inflammatory responses in the jejunal epithelial compartment during infection with Trichinella spiralis. Infect. Immun. 72, 6076-6086. Abstract Article

Kociecka, W. (1993). Early clinical syndromes of severe trichinellosis., In Trichinellosis. Proceedings of the 8th International Conference on Trichinosis., W.S. Campbell, E. Pozio, and F. Bruschi, eds. (Rome: Instituto Superiore di Sanita Press).

Kozek, W.J. (2005). Are bacillary bands responsible for expulsion of Trichinella spiralis? Vet. Parasitol. 132, 69-73. Abstract Article

Krause, M., and Hirsh, D. (1987). A trans-spliced leader sequence on actin mRNA in C. elegans. Cell 49, 753-761. Abstract Article

Kuratli, S., Hemphill, A., Lindh, J., Smith, D.F., and Connolly, B. (2001). Secretion of the novel Trichinella protein TSJ5 by T. spiralis and T. pseudospiralis muscle larvae. Mol. Biochem. Parasitol. 115, 199-208. Abstract Article

Kwan-Lim, G.E., Gregory, W.F., Selkirk, M.E., Partono, F., and Maizels, R.M. (1989). Secreted antigens of filarial nematodes: a survey and characterization of in vitro excreted/secreted products of adult Brugia malayi. Parasite Immunol. 11, 629-654. Abstract

Lang, B.F., M.W., G., and Burger, G. (1999). Mitochondrial genome evolution and the origin of eukaryotes. Annu. Rev. Genet. 33, 351-397. Abstract Article

Larget, B., Holder, M.T., Lewis, P.O., and Swofford, D.L. (2005). Hastings ratio of the local proposal used in Bayesian phylogenetics. Syst. Biol. 54, 961-965. Abstract Article

Lavrov, D., Brown, W., and Boore, J. (2004). Phylogenetic position of the Pentastomida and (pan)crustacean relationships. Proc. Biol. Sci. 271, 537-544. Abstract Article

Lavrov, D.V., and Brown, W.M. (2001). Trichinella spiralis mtDNA: A Nematode Mitochondrial Genome That Encodes a Putative ATP8 and Normally Structured tRNAs and Has a Gene Arrangement Relatable to Those of Coelomate Metazoans. Genetics 157, 621-637. Abstract

Li, C.K., Seth, R., Gray, T., Bayston, R., Mahida, Y.R., and Wakelin, D. (1998). Production of proinflammatory cytokines and inflammatory mediators in human intestinal epithelial cells after invasion by Trichinella spiralis. Infect. Immun. 66, 2200-2206. Abstract

Liu, M., and Boireau, P. (2002). Trichinellosis in China: epidemiology and control. Trends Parasitol. 18, 553-556. Abstract Article

ManWarren, T., Gagliardo, L., Geyer, J., McVay, C., Pearce-Kelling, S., and Appleton, J. (1997). Invasion of intestinal epithelia in vitro by the parasitic nematode Trichinella spiralis. Infect. Immun. 65, 4806-4812. Abstract 
McVay, C.S., Bracken, P., Gagliardo, L.F., and Appleton, J. (2000). Antibodies to tyvelose exhibit multiple modes of interference with the epithelial niche of Trichinella spiralis. Infect. Immun. 68, 1912-1918. Abstract Article

McVay, C.S., Tsung, A., and Appleton, J. (1998). Participation of parasite surface glycoproteins in antibody-mediated protection of epithelial cells against Trichinella spiralis. Infect. Immun. 66, 1941-1945. Abstract

Miroshnichenko, L.S. (1978). Pathomorphology of skeletal muscles in birds infected with Trichinella pseudospiralis. Wiad. Parazytol. 24, 91-96. Abstract

Mitreva, M., Appleton, J., McCarter, J.P., and Jasmer, D.P. (2005). Expressed Sequence Tags from Life Cycle stages of Trichinella spiralis: application to biology and parasite control. Vet. Parasitol. 132, 13-17. Abstract Article

Mitreva, M., Jasmer, D.P., Appleton, J., Martin, J., Dante, M., Wylie, T., Clifton, S.W., Waterston, R.H., and McCarter, J.P. (2004). Gene discovery in the adenophorean nematode Trichinella spiralis: an analysis of transcription from three life cycle stages. Mol. Biochem. Parasitol. 137, 277-291. Abstract Article

Murrell, D., and Bruschi, F. (1994a). Clinical trichinellosis, In Progress in clinical parasitology, T. Sun, ed. (Boca Raton, Fla: CRC Press), pp. 117-150.

Murrell, K.D., and Bruschi, F. (1994b). Clinical trichinellosis. Prog. Clin. Parasitol. 4, 117-150. Abstract

Nilsen, T.W. (1993). Trnas-splicing of nematode premessenger RNA. Annu. Rev. Microbiol. 47, 413-440. Abstract Article

Parkinson, J., Mitreva, M., Whitton, C., Thomson, M., Daub, J., Martin, J., Hall, N., Barrell, B., Waterston, R.H., McCarter, J.P., and Blaxter, M. (2004). A transcriptomic analysis of the phylum Nematoda. Nat. Genet. 36, 1259-1267. Abstract Article

Pawlowski, Z.S. (1983). Clinical aspects in man, In Trichinella and trichinellosis., W.C. Campbell, ed. (New York: Plenum Press).

Penner, G.A., Bush, A., Wise, R., Kim, W., Domier, L., Kasha, K., Laroche, A., Scoles, G., Molnar, S.J., and Fedak, G. (1993). Reproducibility of random amplified polymorphic DNA (RAPD) analysis among laboratories. PCR Methods Appl. 2, 341-345. Abstract

Pennock, J.L., and Grencis, R.K. (2006). The mast cell and gut nematodes: damage and defence. Chem. Immunol. Allergy 90, 128-140. Abstract Article

Polvere, R.I., Kabbash, C.A., Capo, V.A., Kadan, I., and Despommier, D.D. (1997). Trichinella spiralis: synthesis of type IV and type VI collagen during nurse cell formation. Exp. Parasitol. 86, 191-199. Abstract Article

Pozio, E. (2001). New patterns of Trichinella infection. Vet. Parasitol. 98, 133-148. Abstract Article

Pozio, E., Bandi, C., La Rosa, G., Jarvis, T., Miller, I., and Kapel, C.M. (1995). Concurrent infection with sibling Trichinella species in a natural host. Int. J. Parasitol. 25, 1247-1250. Abstract Article

Pozio, E., La Rosa, G., Murrell, K.D., and Lichtenfels, J.R. (1992a). Taxonomic revision of the genus Trichinella. J. Parasitol. 78, 654-659. Abstract Article

Pozio, E., La Rosa, G., Rossi, P., and Murrell, K.D. (1992b). Biological characterization of Trichinella isolates from various host species and geographical regions. J. Parasitol. 78, 647-653. Abstract Article

Pozio, E., and Marucci, G. (2003). Trichinella-infected pork products: a dangerous gift. Trends Parasitol. 19, 338. Abstract Article

Pozio, E., Marucci, G., Casulli, A., Sacchi, L., Mukaratirwa, S., Foggin, C.M., and La Rosa, G. (2004). Trichinella papuae and Trichinella zimbabwensis induce infection in experimentally infected varans, caimans, pythons and turtles. Parasitology 128, 333-342. Abstract Article 
Pozio, E., Serrano, F.J., La Rosa, G., Reina, D., Perez-Martin, E., and Navarrete, I. (1997). Evidence of potential gene flow in Trichinella spiralis and in Trichinella britovi in nature. J. Parasitol. 83, 163-166. Abstract Article

Purkerson, M., and Despommier, D. (1994). Fine structure of the muscle phase of Trichinella spiralis in the mouse. In Trichinellosis, C.W. Kim, ed. (New York: Intext Publishers).

Reason, A.J., Ellis, L.A., Appleton, J.A., Wisnewski, N., Grieve, R.B., McNeil, M., Wassom, D.L., Morris, H.R., and Dell, A. (1994). Novel tyvelose-containing tri- and tetra-antennary N-glycans in the immunodominant antigens of the intracellular parasite Trichinella spiralis. Glycobiology 4, 593-603. Abstract

Ribicich, M., Gamble, H.R., Rosa, A., Bolpe, J., and Franco, A. (2005). Trichinellosis in Argentina: an historical review. Vet. Parasitol. 132, 137-142. Abstract Article

Ribicich, M., Miguez, M., Argibay, T., Basso, N., and Franco, A. (2001). Localization of Trichinella spiralis in muscles of commercial and parasitologic interest in pork. Parasite 8, S246-S248. Abstract

Rijpkema, S.G., Molkenboer, M.J., Schouls, L.M., Jongejan, F., and Schellekens, J.F. (1995). Simultaneous detection and genotyping of three genomic groups of Borrelia burgdorferi sensu lato in Dutch Ixodes ricinus ticks by characterization of the amplified intergenic spacer region between 5S and 23S rRNA genes. J. Clin. Microbiol. 33, 3091-3095. Abstract

Roberts, T., Murrell, K.D., and Marks, S. (1994). Economic losses caused by foodborne parasitic diseases. Parasitol. Today 10, 419-423. Abstract Article

Robinson, M.W., and Connolly, B. (2005). Proteomic analysis of the excretory-secretory proteins of the Trichinella spiralis L1 larva, a nematode parasite of skeletal muscle. Proteomics 5, 4525-4532. Abstract Article

Robinson, M.W., Gare, D.C., and Connolly, B. (2005). Profiling excretory/secretory proteins of Trichinella spiralis muscle larvae by two-dimensional gel electrophoresis and mass spectrometry. Vet. Parasitol. 132, 37-41. Abstract Article

Romaris, F., North, S.J., Gagliardo, L.F., Butcher, B.A., Ghosh, K., Beiting, D.P., Panico, M., Arasu, P., Dell, A., Morris, H.R., and Appleton, J.A. (2002). A putative serine protease among the excretory-secretory glycoproteins of L1 Trichinella spiralis. Mol. Biochem. Parasitol. 122, 149-160. Abstract Article

Rombout, Y.B., Bosch, S., and Van Der Giessen, J.W. B. (2001). Detection and Identification of Eight Trichinella Genotypes by Reverse Line Blot Hybridization. J. Clin. Microbiol. 39, 642-646. Abstract Article

Schmitt, N., Saville, J.M., Greenway, J.A., Stovell, P.L., Friis, L., and Hole, L. (1978). Sylvatic trichinosis in British Columbia: potential threat to human health from an independent cycle. Public Health Rep. 93, 189-193. Abstract

Searcy, D.G., and MacInnis, A.J. (1970). Measurements by DNA renaturation of the genetic basis of parasitic reduction. Evolution 24, 796-806. Article

Smith, M.J., Arndt, A., Gorski, S., and Fajber, E. (1993). The phylogeny of echinoderm classes based on mitochondrial gene arrangements. J. Mol. Evol. 36, 545-554. Abstract Article

Smith, V.P., Selkirk, M.E., and Gounaris, K. (2000). A reversible protein phosphorylation system is present at the surface of infective larvae of the parasitic nematode Trichinella spiralis. FEBS Lett. 483, 104-108. Abstract Article

Sotiraki, S.T., Athanasiou, L.V., Himonas, C.A., Kontos, V.J., and Kyriopoulos, I. (2001). Trichinellosis in Greece: a review. Parasite 8, S83-S85. Abstract

Soule, C., Guillou, J.P., Dupouy-Camet, J., Vallet, C., and Pozio, E. (1993). Differentiation of Trichinella isolates by polymerase chain reaction. Parasitol. Res. 79, 461-465. Abstract Article

Sreter, T., Szell, Z., and Varga, I. (2005). Current knowledge on human trichinellosis. Orv. Hetil. 146, 117-125. Abstract 
Stein, L.D., Bao, Z., Blasiar, D., Blumenthal, T., Brent, M.R., Chen, N., Chinwalla, A., Clarke, L., Clee, C., Coghlan, A., and et al. (2003). The Genome Sequence of Caenorhabditis briggsae: A Platform for Comparative Genomics. PLoS Biol. 1, E45. Abstract Article

Stewart, G.L., Wood, B., and Boley, R.B. (1985). Modulation of host response by Trichinella pseudospiralis. Parasite Immunol. 7, 223-233. Abstract

Su, X.Z., Prestwood, A.K., and McGraw, R.A. (1991). Cloning and expression of complementary DNA encoding an antigen of Trichinella spiralis. Mol. Biochem. Parasitol. 45, 331-336. Abstract Article

Summers, R.W., Elliott, D.E., Urban, J.F. J., Thompson, R.A., and Weinstock, J.V. (2005). Trichuris suis therapy for active ulcerative colitis: a randomized controlled trial. Gastroenterology 128, 825-832. Abstract Article

The C. elegans Sequencing Consortium (1998). Genome Sequence of the Nematode C. elegans: A Platform for Investigating Biology. Science 282, 2012-2018. Abstract Article

Ursell, P.C., and et al (1984). Myocarditis caused by Trichinella spiralis. Arch. Pathol. Lab. Med. 108, 4-5. Abstract

Vanfleteren, J.R., Van de Peer, Y., Blaxter, M.L., Tweedie, S.A., Trotman, C., Lu, L., Van Hauwaert, M.L., and Moens, L. (1994). Molecular genealogy of some nematode taxa as based on cytochrome c and globin amino acid sequences. Mol. Phylogenet. Evol. 3, 92-101. Abstract Article

Vassilatis, D.M., Despommier, D., Misek, D., Polvere, R., Gold, A.M., and Van der Ploeg, L.H. T. (1992). Analysis of a 43-kDa glycoprotein from the intracellular parasitic nematode Trichinella spiralis. J. Biol. Chem. 267, 18459-18465. Abstract

Voronov, D.A. (2001). Comparative embryology of nematodes and the law of embryo similarity. Zh. Obshch. Biol. $62,34-48$. Abstract

Voronov, D.A., Panchin, Y.V., and Spiridonov, S.E. (1998). Nematode phylogeny and embryology. Nature 395, 28-28. Abstract Article

Williams, J.G. K., Kubelik, A.R., Livak, K.J., Rafalski, J.A., and Tingey, S.V. (1990). DNA polymorphisms amplified by arbitrary primers are useful as genetic markers. Nucleic Acids Res. 18, 6531-6535. Abstract

Winska, P., Golos, B., Ciesla, J., Zielinski, Z., Fraczyk, T., Walajtys-Rode, E., and Rode, W. (2005). Developmental arrest in Caenorhabditis elegans dauer larvae causes high expression of enzymes involved in thymidylate biosynthesis, similar to that found in Trichinella muscle larvae. Parasitology 131, 247-254. Abstract Article

Wisnewski, N., McNeil, M., Grieve, R.B., and Wassom, D.L. (1993). Characterization of novel fucosyl- and tyvelosyl-containing glycoconjugates from Trichinella spiralis muscle stage larvae. Mol. Biochem. Parasitol. 61, 25-35. Abstract Article

Wisnewski, N., Zhang, J., Bundle, D.R., and Wassom, D.L. (1997). Use of a novel synthetic $\mathcal{Q}^{-t y v e l o s e-G a l N a c}$ neoglycan in serological detection of Trichinella spiralis infection., In Trichinellosis ICT9, G. Ortega-Pierres, H.R. Gamble, F. van Knapen, and D. Wakelin, eds. (Mexico: CINVESTAV), pp. 463-468.

Wu, Z., Nagano, I., and Takahashi, Y. (1998). The detection of Trichinella with polymerase chain reaction (PCR) primers constructed using sequences of random amplified polymorphic DNA (RAPD) or sequences of complementary DNA encoding excretory-secretory (E-S) glycoproteins. Parasitology 117, 173-183. Abstract Article

Wu, Z., Nagano, I., and Takahashi, Y. (1999). A panel of antigens of muscle larvae of Trichinella spiralis and T. pseudospiralis as revealed by two-dimensional western blot and immunoelectron microscopy. Parasitology 118, 615-622. Abstract Article 
Wylie, T., Martin, J., Dante, M., Mitreva, M., Clifton, S.W., Chinwalla, A., Waterston, R.H., Wilson, R.K., and McCarter, J.P. (2004). Nematode.net: A Tool for Navigating Sequences from Parasitic and Free-Living Nematodes. Nucleic Acids Res. 32, D423-D426. Abstract Article

Yao, C., Bohnet, S., and Jasmer, D.P. (1998). Host nuclear abnormalities and depletion of nuclear antigens induced in Trichinella spiralis-infected muscle cells by the anthelmintic mebendazole. Mol. Biochem. Parasitol. 96, 1-13. Abstract Article

Yao, C., and Jasmer, D.P. (1998). Nuclear antigens in Trichinella spiralis infected muscle cells: nuclear extraction, compartmentalization and complex formation. Mol. Biochem. Parasitol. 92, 207-218. Abstract Article

Yao, C., and Jasmer, D.P. (2001). Trichinella spiralis infected muscle cells: high levels of RNA polymerase II in nuclear speckle domains and depletion by mebendazole treatment. Infect. Immun. 69, 4065-4071. Abstract Article

Yera, H., Andiva, S., Perret, C., Limonne, D., Boireau, P., and Dupouy-Camet, J. (2003). Development and Evaluation of a Western Blot Kit for Diagnosis of Human Trichinellosis. Clin. Diagn. Lab. Immunol. 10, 793-796. Article

Zarlenga, D.S., Chute, M.B., Martin, A., and Kapel, C.M. (2001). A single, multiplex PCR for differentiating all species of Trichinella. Parasite 8, S24-S26. Abstract

Zarlenga, D.S., Chute, M.B., Martin, A., and Kapel, C.M. O. (1999). A multiplex PCR for unequivocal differentiation of all encapsulated and non-encapsulated genotypes of Trichinella. Int. J. Parasitol. 29, 1859-1867. Abstract Article

Zarlenga, D.S., La Rosa, G., Pozio, E., and Rosenthal, B. (2004). Identification and classification within the genus Trichinella, with special emphasis on non-encapsulated species. Vet. Parasitol. 125, 75-78.

Zarlenga, D.S., Rosenthal, B.M., La Rosa, G., Pozio, E., and Hoberg, E.P. (2006). Post-Miocene expansion, colonization, and host switching drove speciation among extant nematodes of the archaic genus Trichinella. Proc. Natl. Acad. Sci. U.S.A. 103, 7354-7359. Abstract Article

All WormBook content, except where otherwise noted, is licensed under a Creative Commons Attribution License. 